\title{
HPTLC Fingerprint Profile and Isolation of Marker Compound of Ruellia tuberosa
}

\author{
Daya L. Chothani, ${ }^{1}$ M. B. Patel, ${ }^{2}$ and S. H. Mishra ${ }^{2}$ \\ ${ }^{1}$ Pharmacognosy Department, Pioneer Pharmacy Degree College, Ajwa-Nimeta Road, Sayajipura, Vadodara 390019, India \\ ${ }^{2}$ Herbal Drug Technology Lab, Pharmacy Department, Faculty of Technology and Engineering, \\ The M. S. University of Baroda, Vadodara 390 001, India \\ Correspondence should be addressed to Daya L.Chothani, daya.herb@gmail.com
}

Received 14 June 2011; Revised 21 September 2011; Accepted 30 September 2011

Academic Editor: Monika Waksmundzka-Hajnos

Copyright (๑) 2012 Daya L. Chothani et al. This is an open access article distributed under the Creative Commons Attribution License, which permits unrestricted use, distribution, and reproduction in any medium, provided the original work is properly cited.

The present study was aimed to identification, isolation, and quantification of marker in $R$. tuberosa (Acanthaceae). HPTLC fingerprinting was carried out for various extract of root, stem, and leaf of $R$. tuberosa. From the HPTLC fingerprint the florescent band (under $366 \mathrm{~nm}$ ) at $R_{f}: 0.56$ (mobile phase chloroform : toluene : ethyl acetate $(6: 3: 1, \mathrm{v} / \mathrm{v})$ ) was found in leaf, root, and stem of $R$. tuberosa. So, the florescent band (under $366 \mathrm{~nm}$ ) at $R_{f}: 0.56$ was isolated as marker compound RT-F2 from root of $R$. tuberosa. The marker compound RT-F2 was quantified by using HPTLC technique. The percentage (W/W) amount of RT-F2 was found to $40.0 \%$ and $44.6 \%$ in petroleum ether and ethyl acetate extract of $R$. tuberosa roots, respectively. Further study is suggested to characterization and biological nature of marker compound.

\section{Introduction}

Marker compound means chemical constituents within a medicinal that can be used to verify its potency or identity. For sometimes, the marker compounds may be described as active ingredients or chemicals that confirm the correct botanical identity of the starting material. It is very difficult to identify correct marker compounds for all traditional medicinals, because some medicinals have unknown active constituents and others have multiple active constituents. A chromatographic fingerprint of a herbal medicine is a chromatographic pattern of the extract of some common chemical components of pharmacologically active and/or chemical characteristics. By using chromatographic fingerprints, the authentication and identification of herbal medicines can be accurately conducted even if the amount and/or concentration of the chemically characteristic constituents is not exactly the same for different samples of drug. Hence it is very important to obtain reliable chromatographic fingerprints that represent pharmacologically active and chemically characteristic component of the herbal drug [1-5].
Ruellia tuberosa is an erect, suberect, or diffuse perennial herb up to $60-70 \mathrm{~cm}$ tall herb and belongs to family Acanthaceae, a native of Central America, introduced into Indian garden as ornament. It is used medicinally in West Indies, Central America, Guiana, and Peru. R. tuberosa is commonly known as "Cracker plant" [6-8]. In Siddha system of medicine, leaves are given with liquid copal as remedy for gonorrhea and ear diseases [9], used in stomach cancer [10]. Dried and ground roots in dose of two ounces cause abortion and also used in sore eyes [11]. The herb also exhibits emetic activity and employed substitute of ipecac, also used in bladder stones and decoction of leaves used in treatment of Bronchitis [12]. In Suriname's traditional medicine system, it is used as anthelmintic and also in management of joint pain and strained muscles. In folk medicine, it has been used as diuretic, antipyretic, antidiabetic, antidotal, thirst-quenching agent and analgesic and anti-hypertensive activity [13, 14]. Ruellia tuberosa is used as cooling in urinary problem, uterine fibroids $[15,16]$. It has recently been incorporated as a component in a herbal drink in Taiwan [17]. It has been experimentally proved to possess antioxidant [18], antimicrobial 
[19], anticancer [20], gastroprotective activity [21], antinociceptive, and anti-inflammatory activity [22]. It is reported that it contains flavonoids, steroids, and triterpenoids and alkaloid [23-26]. But there is no any identified marker reported; so the present study is aimed to identification, isolation, and quantification of marker in $R$. tuberose.

\section{Materials and Methods}

2.1. Plant Material. Fresh plant of Ruellia tuberosa was collected from the campus of The M. S. University of Baroda in the month of August 2008. Plant was authenticated at Botany Department of The M. S. University. Voucher specimen (PHR/HDT/DC-RT-08) was stored in herbarium of our laboratory. Roots were separated and sun dried separately. Dried plant material was powdered.

2.2. Chemicals. All other reagents were analytical grade, purchased from Merck (Darmstadt, Germany). All UV-Vis measurements were recorded on a Shimadzu UV-1800.

2.3. Preparation of Extracts [27]. Powdered air dried drug, weighing about $50 \mathrm{~g}$, was extracted successively in soxhlet apparatus with the series of solvents of increasing polarity as follows: petroleum ether, toluene, chloroform, ethyl acetate, and methanol. Each time before extracting with the next solvent, the material was dried. All the extracts were filtered through Whatman filter paper and concentrated. Concentrated extracts were applied on the TLC plate as sample solution.

\subsection{HPTLC Finger Print Profiles for Various Extracts [28, 29]}

2.4.1. TLC Conditions. TLC plate consists of $20 \times 10 \mathrm{~cm}$, precoated with silica gel 60 F254 TLC plates (E. Merck) $(0.2 \mathrm{~mm}$ thickness) with aluminum sheet support. The spotting device was a CAMAG Linomat V Automatic Sample Spotter (Camag Muttenz, Switzerland); the syringe, $100 \mu \mathrm{L}$ (from Hamilton); the developing chamber was a CAMAG glass twin trough chamber $(20 \times 10 \mathrm{~cm})$; the densitometer consisted of a CAMAG TLC scanner 3 linked to WINCATS software. Mobile phase was chloroform:toluene: ethyl acetate $(6: 3: 1, \mathrm{v} / \mathrm{v})$. Saturation time for mobile phase was 2 hours.

2.4.2. Procedure. Various extracts of roots, leaf, and stem of $R$. tuberosa were applied on TLC plate and the plate was developed in chloroform: toluene: ethyl acetate $(6: 3: 1, \mathrm{v} / \mathrm{v})$ solvent system to a distance of $8 \mathrm{~cm}$. The plates were dried at room temperature in air. The plate was scanned at $254 \mathrm{~nm}$ (Figure 1) and $366 \mathrm{~nm}$ (Figure 2) before spraying and at $600 \mathrm{~nm}$ (Figure 3) after spraying with detection reagent (Anisaldehyde sulfuric acid reagent and plate was heated at $110^{\circ} \mathrm{C}$ for 5 minutes). The $R_{f}$ values and color of the resolved bands were noted.

\subsection{Isolation and Characterization of Chemical Marker}

2.5.1. Isolation of Compound RT-F2 from Petroleum Ether and Ethyl Acetate Extract of Root. The dried powder of root

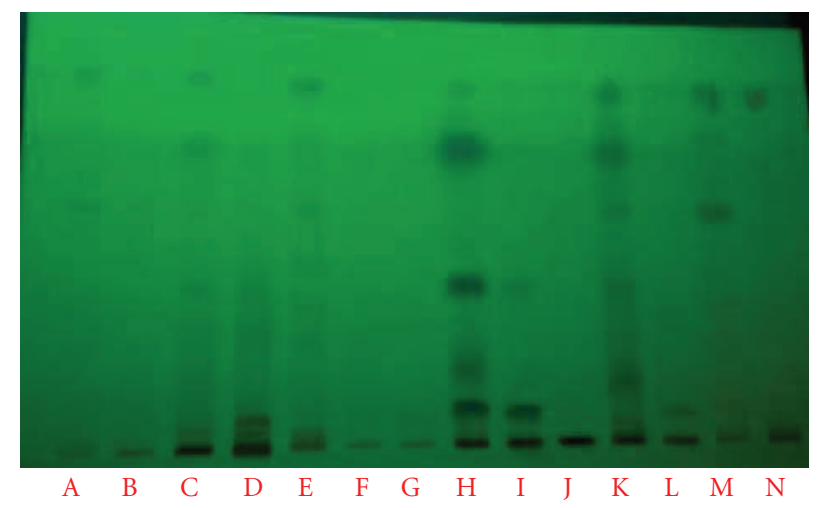

FiguRE 1: HPTLC fingerprint of various extracts of $R$. tuberosa at $254 \mathrm{~nm}$.

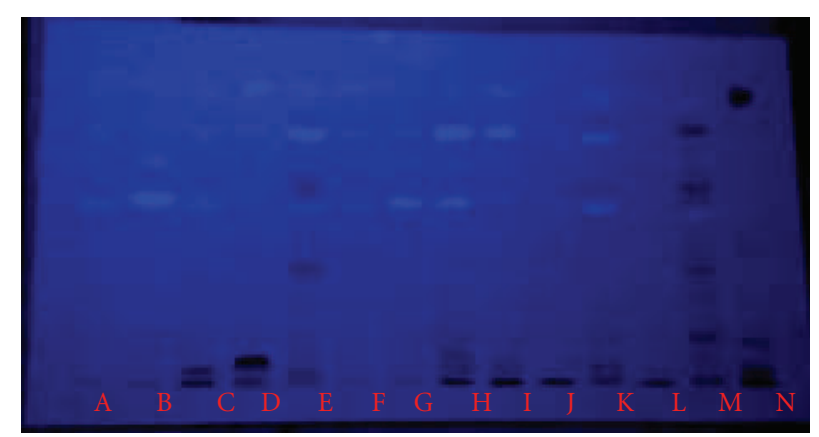

FIGURE 2: HPTLC fingerprint of various extracts $R$. tuberosa at $366 \mathrm{~nm}$.

$(200 \mathrm{~g})$ was extracted with petroleum ether and ethyl acetate $(500 \mathrm{~mL})$ separately in soxhlet apparatus for 2 days. Then the extracts were concentrated by distilling the solvent and concentrated extracts were subjected to repetitive preparative thin layer chromatography using Silica Gel G as stationary phase $(20 \times 20 \mathrm{~cm}$ glass plates $)$ and chloroform: toluene: ethyl acetate $(6: 3: 1 \mathrm{v} / \mathrm{v} / \mathrm{v})$ as mobile phase. Fluorescents bands under $366 \mathrm{~nm}$ at $R_{f}$ value 0.56 were identified RT-F2 compound. RT-F2 bands were scraped. RT-F2 was separated from silica Gel G by treating with methanol and Chloroform mixture $(1: 1)$, filtered through Whatman filter paper, and filtrates were combined, concentrated, and dried. Isolated compounds were subjected to TLC and HPTLC, UV spectroscopy (Figure 4), IR spectroscopy (Figure 5), and Mass spectroscopy (Figure 6).

\subsubsection{Quantification of RT-F2 in Petroleum Ether and Ethyl Acetate Extract Using HPTLC Method}

Standard Stock Solution. A solution of F2 compound $(500 \mu \mathrm{g} / \mathrm{mL})$ was prepared in chloroform.

\section{Sample Preparation}

Ethyl Acetate Extract. Stock solution of sample $2 \mathrm{mg} / \mathrm{mL}$ of extract was prepared in chloroform. 


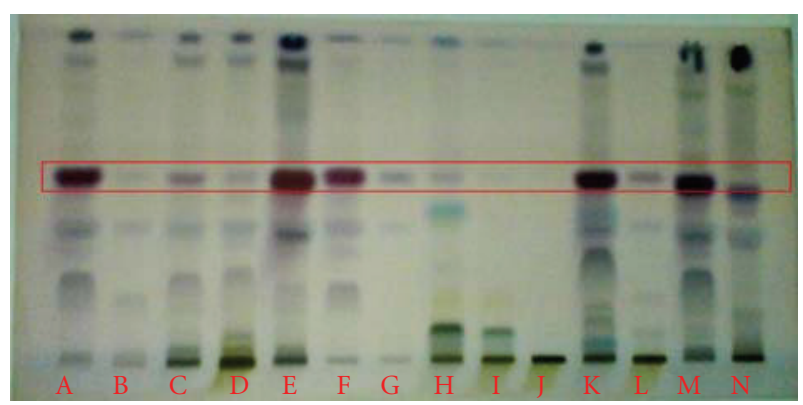

Figure 3: HPTLC fingerprint of various extracts of $R$. tuberosa at $600 \mathrm{~nm}$. (A) Petroleum Ether extract (R). (B) Toluene extract (R). (C) Chloroform extract (R). (D) EtOH extract (R). (E) Petroleum Ether Fraction (R). (F) Hexane Fraction (R). (G) Toluene Fract (R). (H) Chloroform Fract (R). (I) EtOH Fract (R). (J) Methanol Fract (R). (K) EtOH extract (R). (L) methanol extract (R). (M) Petroleum Ether extract (S). (N) petroleum ether (L). R: root; Fract: hydroalcoholic fraction; L: Leaf; S: stem.

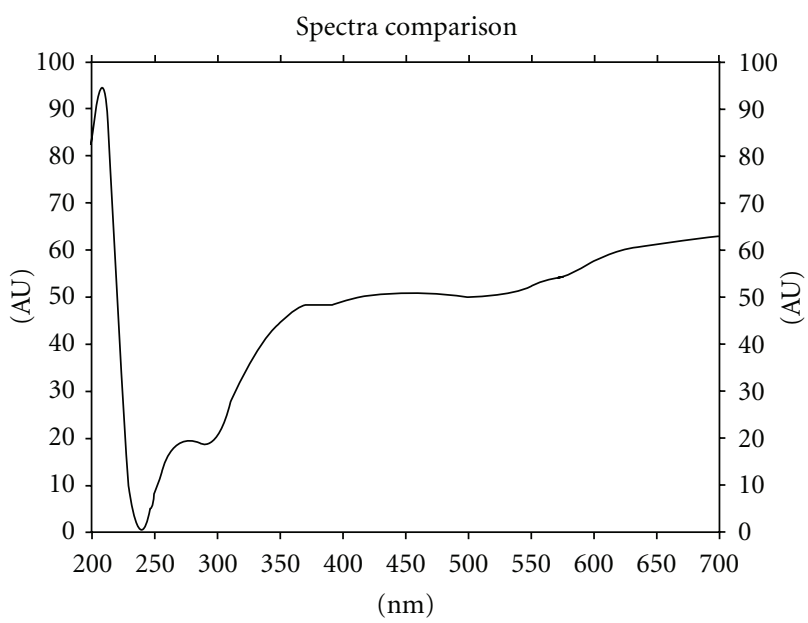

Figure 4: UV spectra of RT-F2 compound ( $\left.\lambda_{\max } 208 \mathrm{~nm}, 272 \mathrm{~nm}\right)$.

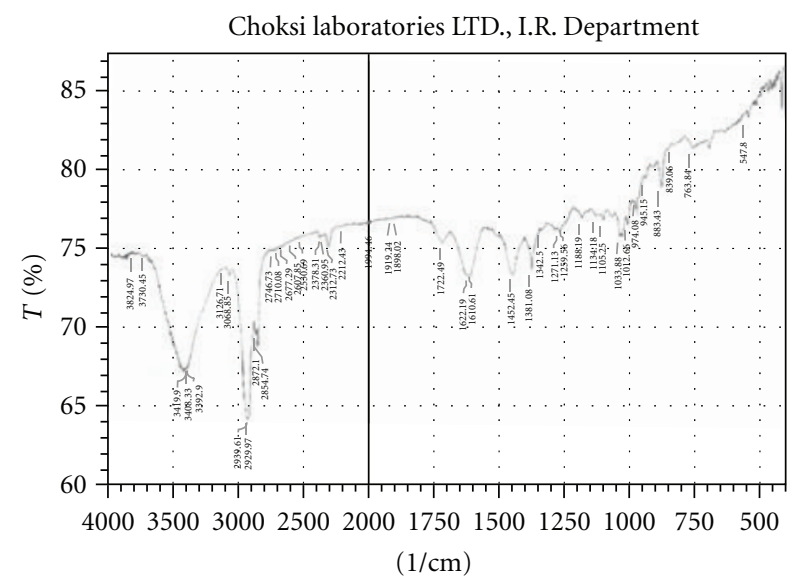

FIGURE 5: IR spectra of RT-F2 compound.

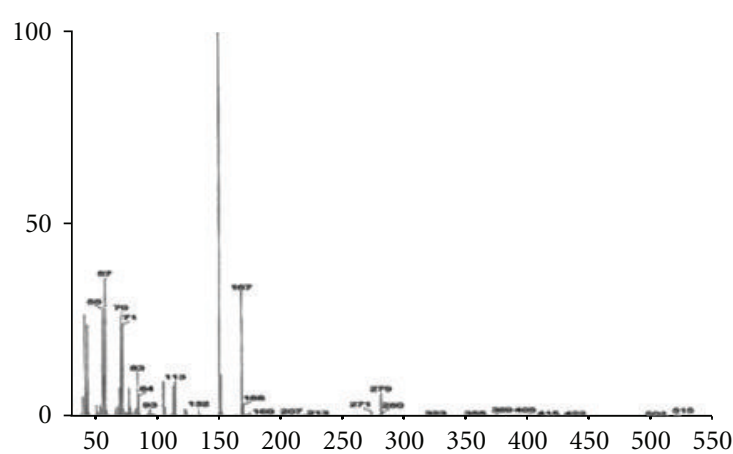

FIgURE 6: Mass spectra of RT-F2 compound.

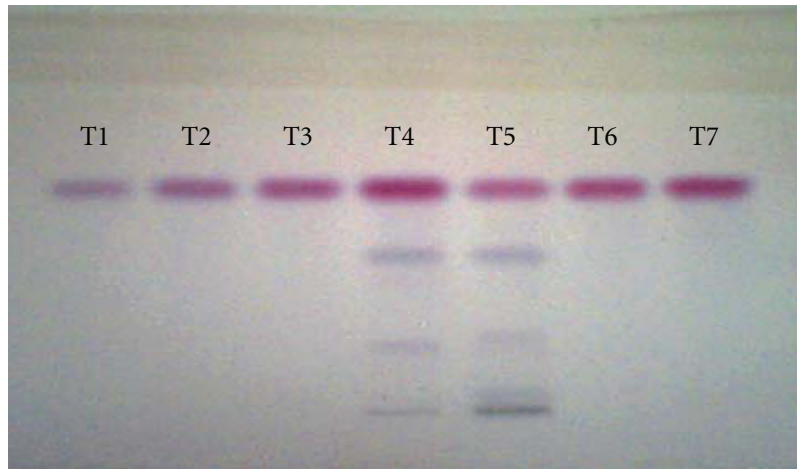

Figure 7: Densitogram of RT-F2 compound at $600 \mathrm{~nm}$, where T1, T2, T3, T6, and T7 are 1.25, 2.5, 3.75, 5.0, and 6.25 concentration of standard RT-F2 $(\mu \mathrm{g} / \mathrm{mL})$, respectively. T4 and T5 are petroleum ether extract and ethyl acetate extract $(\mu \mathrm{g} / \mathrm{mL})$, respectively.

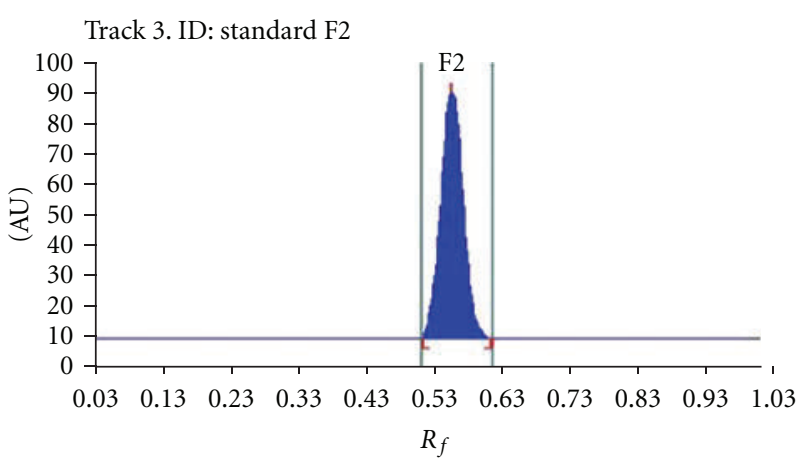

FIgURE 8: Chromatogram of RT-F2 standard compound at $600 \mathrm{~nm}$.

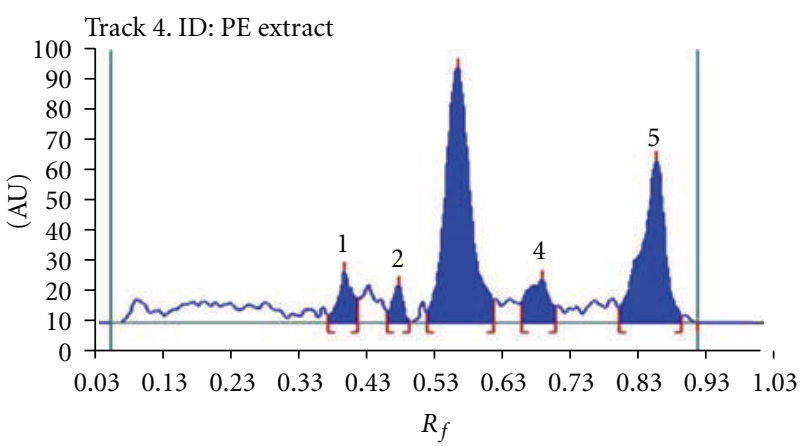

FiguRE 9: Chromatogram of petroleum ether extract at $600 \mathrm{~nm}$. 


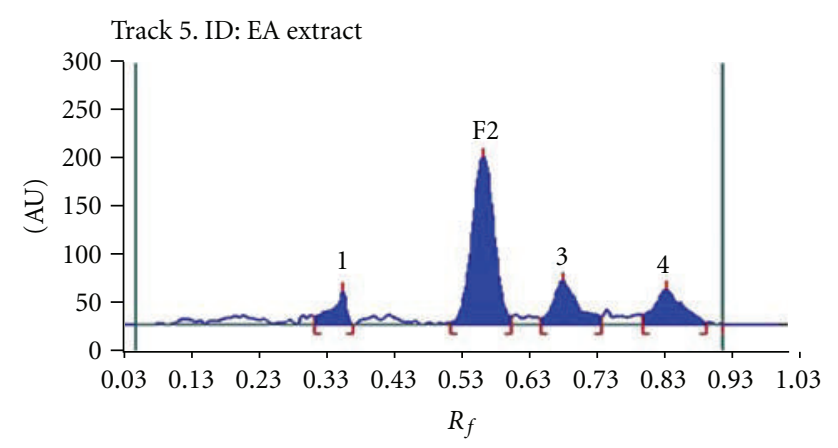

Figure 10: Chromatogram of ethyl acetate extract at $600 \mathrm{~nm}$.

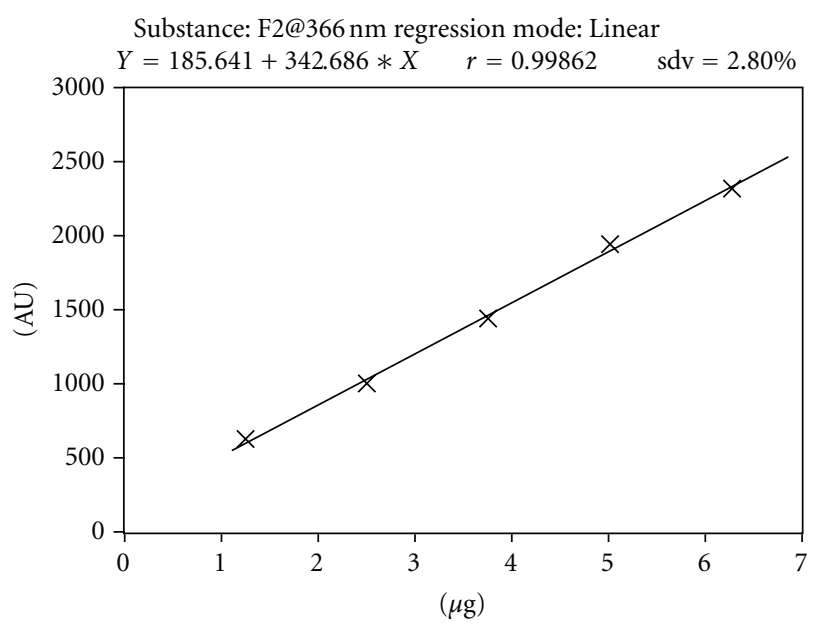

FIGURE 11: Calibration curve of RT-F2 compound.

Petroleum Ether Extract. Stock solution of sample $1 \mathrm{mg} / \mathrm{mL}$ of extract was prepared in chloroform.

Calibration Curve. From the standard stock solution 2.5$12.5 \mu \mathrm{L}$ solutions were applied on precoated plate of Silica Gel $\mathrm{G}$, to produce the range of $1.25-6.25 \mu \mathrm{g}$ of RT-F2 per spot, respectively (Figure 7). Calibration curve is given in Figure 11.

Sample. A $10 \mu \mathrm{L}$ of each extract was applied.

Mobile Phase. The mobile phase was chloroform:toluene: ethyl acetate $(6: 3: 1)$.

Stationary Phase. The stationary phase was Precoated plate, Silica Gel G 60 F254.

Applicator. The applicator phase was CAMAG LINOMAT 5.

Development. Plate was developed in a twin trough chamber.

Detection. We spray with Anisaldehyde sulfuric acid reagent and heat at $110^{\circ} \mathrm{C}$ for 5 minutes.

The plate was scanned at $366 \mathrm{~nm}$ under fluorescent mode before spraying and at $600 \mathrm{~nm}$ (Figure 7) after spraying. The Chromatograph of RT-F2 standard compound (Figure 8), petroleum ether extracts (Figure 9), and ethyl acetate extract (Figure 10) were reported.

\section{Results and Discussion}

3.1. HPTLC Fingerprint Profile. HPTLC fingerprint showed that purple colored band (after derivatisation) (Figure 3) at $R_{f}: 0.56$ was found in leaf, root, and stem of $R$. tuberosa. The florescent band (under $366 \mathrm{~nm}$ ) at $R_{f}: 0.56$ was selected as marker compound and identified as RT-F2.

3.2. Isolation and Characterization of Marker RT-F2 Compound. Data from fingerprinting results provide information about presence of major terpenoid in petroleum ether extract and ethyl acetate extract of root, targeted for isolation.

3.3. Compound RT-F2. Isolated compound F2 has sticky type of nature. It gives violet purple color with Anisaldehyde sulfuric acid reagent and Liebermann-Burchard reagent.

\section{Analysis}

TLC. $R_{f}: 0.56$, Solvent system-toluene: chloroform : ethyl acetate $(3: 6: 1)$.

Detection. Anisaldehyde sulfuric acid reagent (heat at $105^{\circ} \mathrm{C}$ for 5 minutes.

$\operatorname{IR}\left(\mathrm{KBr}, \mathrm{cm}^{-1}\right) .3409,1622$.

MS. $(\mathrm{m} / \mathrm{z}) 279,167,149,113,83,55$.

3.4. Quantification of RT-F2 in Petroleum Ether and Ethyl Acetate Extract Using HPTLC. Figure 7 shows the HPTLC chromatogram of standard RT-F2 compound, petroleum ether extract and ethyl acetate extract.

The percentage (W/W) amount of RT-F2 was found to $40.0 \%$ and $44.6 \%$ in petroleum ether and ethyl acetate extract of $R$. tuberosa roots, respectively (Tables 1 and 2).

\section{Conclusion}

Herbal medicines are composed of many constituents and are therefore very capable of variation. Hence it is very important to obtain reliable chromatographic fingerprints that represent pharmacologically active and chemically characteristic components of the herbal medicine. HPTLC fingerprinting profile is very important parameter of herbal drug standardization for the proper identification of medicinal plants. A TLC densitometric method for the quantification of isolated marker compound RT-F2 was established in petroleum ether and ethyl acetate extract of roots of $R$. tuberosa. The present HPTLC fingerprinting profile can be used as a diagnostic tool to identity and to determine the quality and purity of the R. tuberosa in future studies. 
TABLE 1: Calibration curve data for RT- F2 compound of HPTLC method.

\begin{tabular}{|c|c|c|c|c|c|c|}
\hline Track & $R_{f}$ & Concentration of RT-F2 & Height of peak & Calculated RT-F2 & Area of peak & Calculated RT-F2 \\
\hline 1 & 0.57 & $1.250 \mu \mathrm{g}$ & 51.72 & & 641.96 & \\
\hline 2 & 0.56 & $2.500 \mu \mathrm{g}$ & 48.37 & & 1005.73 & \\
\hline 3 & 0.56 & $3.750 \mu \mathrm{g}$ & 71.26 & & 1446.38 & \\
\hline 4 & 0.56 & Unknown* & 73.75 & $3.758 \mu \mathrm{g}$ & 1558.45 & $4.006 \mu \mathrm{g}$ \\
\hline 5 & 0.57 & Unknown** & 158.38 & $>6.875 \mu \mathrm{g}$ & 3246.91 & $>6.875 \mu \mathrm{g}$ \\
\hline 6 & 0.57 & $5.000 \mu \mathrm{g}$ & 86.79 & & 1945.75 & \\
\hline 7 & 0.58 & $6.250 \mu \mathrm{g}$ & 110.10 & & 2313.74 & \\
\hline
\end{tabular}

${ }^{*}$ Petroleum ether extract, ${ }^{* *}$ Ethyl acetate extract

Regression equation (Height) $Y=27.094+12.415 X, r=0.9574$

Regression equation (Area) $Y=185.641+342.686 X, r=0.9986$.

TABLE 2: Quantification of RT-F2 compound.

\begin{tabular}{ll}
\hline $\begin{array}{l}\text { Stationary phase } \\
\text { Mobile phase }\end{array}$ & $\begin{array}{l}\text { Precoated Silica Gel } 60 \mathrm{GF}_{254} \\
\text { Chloroform : toluene : ethyl acetate }(6: 3: 1)\end{array}$ \\
$\begin{array}{ll}\text { Calibration range of } \\
\text { F2 }\end{array}$ \\
$\begin{array}{ll}\text { Detection } & \text { Anisaldehyde sulphuric acid reagent heated } \\
\text { at } 110^{\circ} \mathrm{C} \text { for } 5 \text { min and detected at } 600 \mathrm{~nm} .\end{array}$ \\
$\begin{array}{ll}\text { Regression equation } \\
R \text { value }\end{array}$ & $\begin{array}{l}Y=189.6+342.686 X \\
\text { (area wise) }\end{array}$ \\
\hline
\end{tabular}

\section{References}

[1] http://www.bluepoppy.com/blog/blogs/blog1.php/what-aremarker-compounds.

[2] P. S. Patil and R. Shettigar, "An advancement of analytical techniques in herbal research," Journal of Advanced Scientific Research, vol. 1, no. 1, pp. 8-14, 2010.

[3] Y. Z. Liang, P. Xie, and K. Chan, "Quality control of herbal medicines," Journal of Chromatography B, vol. 812, no. 1-2, pp. 53-70, 2004.

[4] E. S. Ong, "Chemical assay of glycyrrhizin in medicinal plants by pressurized liquid extraction (PLE) with capillary zone electrophoresis (CZE)," Journal of Separation Science, vol. 25, no. 13, pp. 825-831, 2002.

[5] P. S. Xie, "A feasible strategy for applying chromatography fingerprint to assess quality of Chinese herbal medicine," Traditional Chinese Drug Research \& Clinical Pharmacology, vol. 12, no. 3, pp. 141-169, 2001.

[6] C. N. Pandey, Medicinal Plants of Gujarat, Gujarat Ecological Education and Research Foundation, Gujarat, India, 2005.

[7] Medicinal Plants of the Guiana's (Guyana, Surinam, French Guiana).

[8] D. L. Chothani, M. B. Patel, H. U. Vaghasiya, and S. H. Mishira, "Review on Ruellia tuberosa (cracker plant)," Pharmacognosy Journal, vol. 2, no. 12, pp. 506-512, 2010.

[9] L. Suseela and S. Prema., "Pharmacognostic study on Ruellia tuberosa," Journal of Medicinal and Aromatic Plant Sciences, vol. 29, pp. 117-122, 2007.

[10] M. B. Reddy, K. R. Reddy, and M. N. Reddy, "Ethnobotany of Cuddapah district, Andhra Pradesh, India," International Journal of Pharmacognosy, vol. 29, no. 4, pp. 273-280, 1991.

[11] B. D. Kirtikar and B. D. Basu, Indian Medicinal Plants, vol. 3, International Book Distributors, Deheradun, India, 1935.
[12] The Wealth Of India, A Dictionary Of Indian, Raw Material and Industrial Product, Publication and Information Directorate, Council of Scientific and Industrial Research, New Delhi, India, 1972.

[13] N. Y. Chiu and K. H. Chang, "The illustrated medicinal plants of Taiwan," Mingtong Medical Journal, vol. 226, no. 1, 1995.

[14] F. A. Chen, A. B. Wu, P. Shieh, D. H. Kuo, and C. Y. Hsieh, "Evaluation of the antioxidant activity of Ruellia tuberosa," Food Chemistry, vol. 94, no. 1, pp. 14-18, 2006.

[15] C. A. Lans, Creole remedies. Case studies of ethnoveterinary medicine in Trinidad and Tobago, Ph.D.Dissertation, Wageningen University, Wageningen, The Netherlands, 2001, no. 2992.

[16] C. A. Lans, "Ethnomedicines used in Trinidad and Tobago for urinary problems and diabetes mellitus," Journal of Ethnobiology and Ethnomedicine, vol. 2, article 45, pp. 1-11, 2006.

[17] M. J. Balick, F. Kronenberg, A. L. Ososki et al., "Medicinal plants used by latino healers for women's health conditions in New York City," Economic Botany, vol. 54, no. 3, pp. 344-357, 2000.

[18] F. A. Chen, A. B. Wu, P. Shieh, D. H. Kuo, and C. Y. Hsieh, "Evaluation of the antioxidant activity of Ruellia tuberosa," Food Chemistry, vol. 94, no. 1, pp. 14-18, 2006.

[19] C. Wiart, M. Hannah, M. Yassim, H. Hamimah, and M. Sulaiman, "Anti-microbial activity of Ruellia tuberosa L," American Journal of Chinese Medicine, vol. 33, no. 4, pp. 683685, 2005.

[20] S. Arun, P. Giridharan, A. Suthar et al., Isolation of Tylocrebrine from Ruellia tuberosa through Bioassay Directed Column Chromatography and Elucidating its Anti-Cancer and AntiInflammatory Potential, 7th Joint Meeting of GA, AFERP, ASP, PSI \& SIF, Athens, Greece, 2008.

[21] L. S. R. Arambewela, R. Thambugala, and W. D. Ratnasooriya, "Gastroprotective activity of Ruellia tuberosa root extract in rats," Journal of Tropical Medicinal Plants, vol. 4, no. 2, pp. 191194, 2003.

[22] M. A. Alam, N. Subhan, M. A. Awal et al., "Antinociceptive and anti-inflammatory properties of Ruellia tuberosa," Pharmaceutical Biology, vol. 47, no. 3, pp. 209-214, 2009.

[23] C. F. Lin, Y. L. Huang, L. Y. Cheng et al., "Bioactive flavonoid from Ruellia tuberosa," The Journal of Chinese Medicine, vol. 17, no. 3, pp. 103-109, 2006.

[24] S. S. Subramanian and A. G. R. Nair, "Apigenin glycoside from thunbergia fragrans and Ruellia tuberosa," Current Science, p. 480, 1974.

[25] R. S. Singh, H. S. Pandey, B. K. Singh, and R. P. Pandey, "A new triterpenoid from Ruellia tuberosa linn," Indian Journal of Chemistry B, vol. 41, no. 8, pp. 1754-1756, 2002. 
[26] C. K. Andhiwal and R. P. Chandra Haas Varshney, "Phytochemical investigation of Ruellia tuberosa L," Indian Drugs, vol. 23, no. 49, 1985.

[27] C. K. Kokate, Practical Pharmacognosy, Vallabh Prakashan, New Delhi, India, 4th edition, 2005.

[28] H. Wagner, S. Blade, and G. M. Zgainsky, Plant Drug Analysis, Springer, Great Britain, UK, 1984.

[29] E. Stahl, "Thin layer chromatography," in A Laboratory Hand Book, Springer, Berlin, Germany, 2nd edition, 1965. 


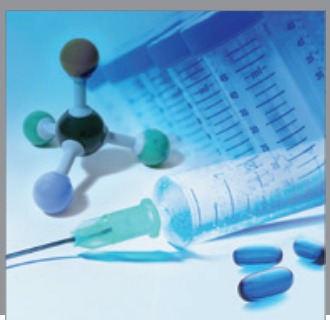

International Journal of

Medicinal Chemistry

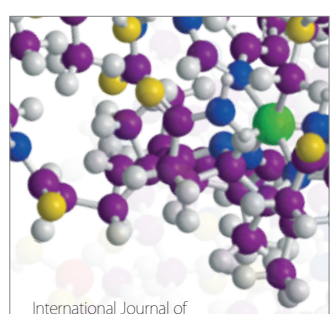

Carbohydrate Chemistry

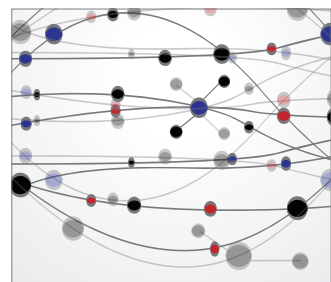

The Scientific World Journal
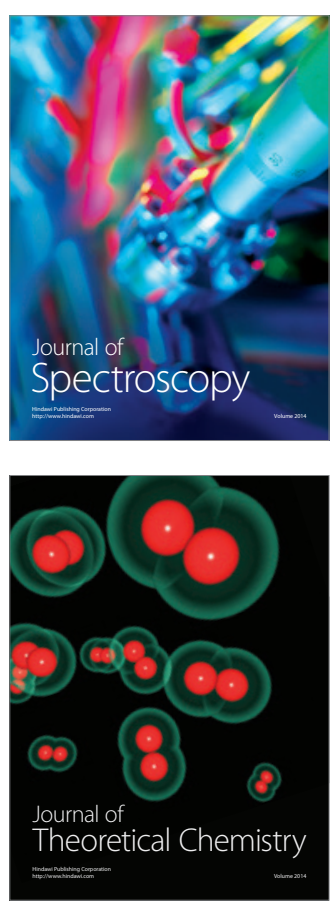
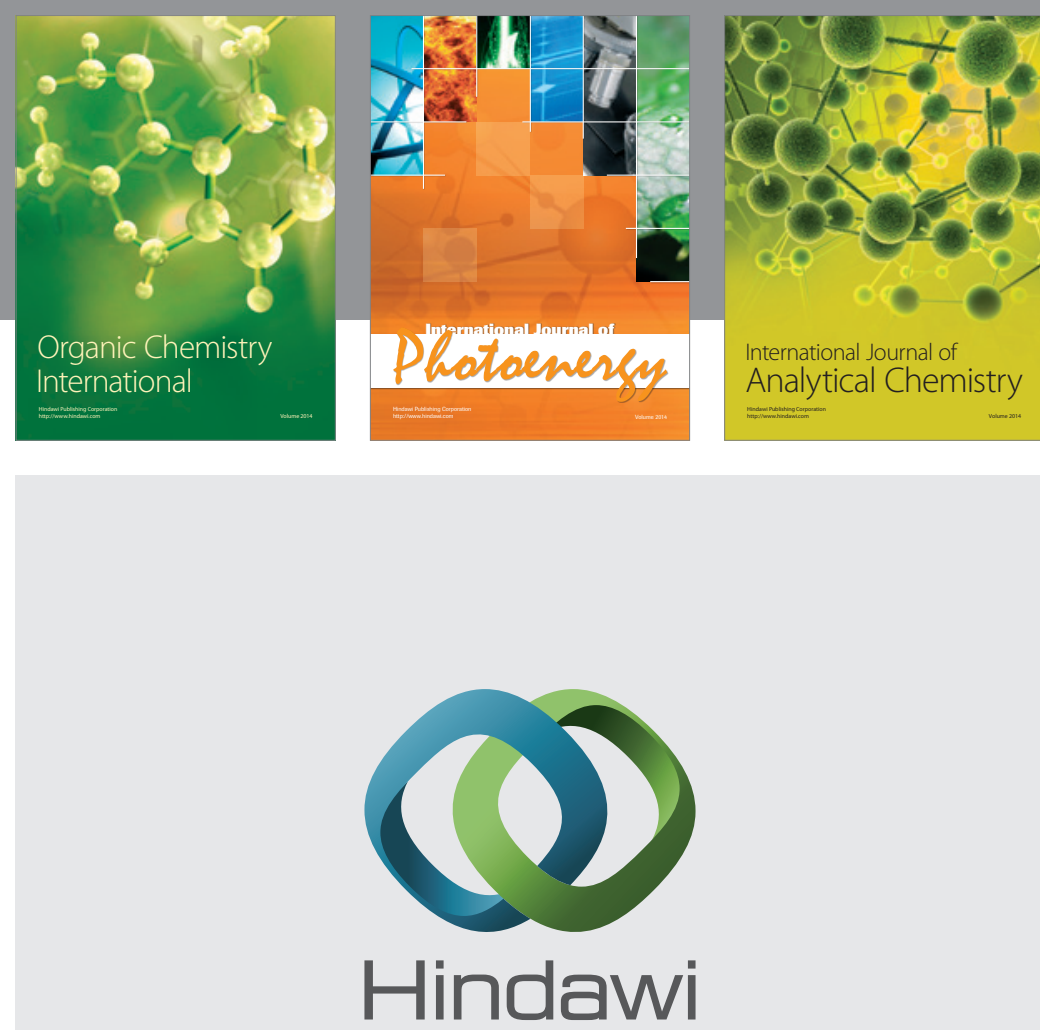

Submit your manuscripts at

http://www.hindawi.com
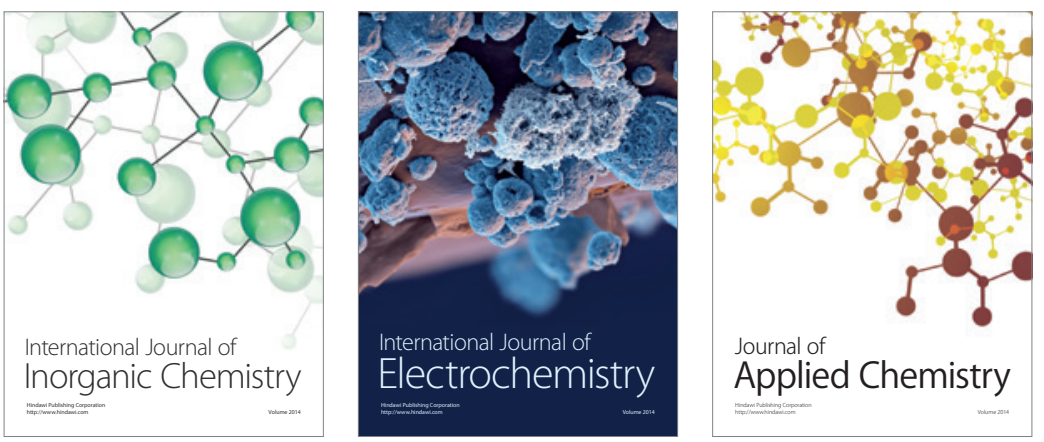

Journal of

Applied Chemistry
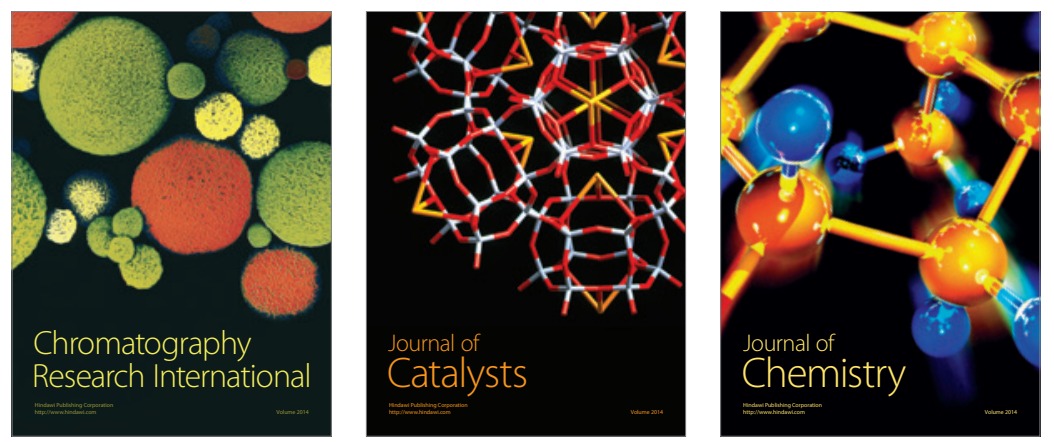
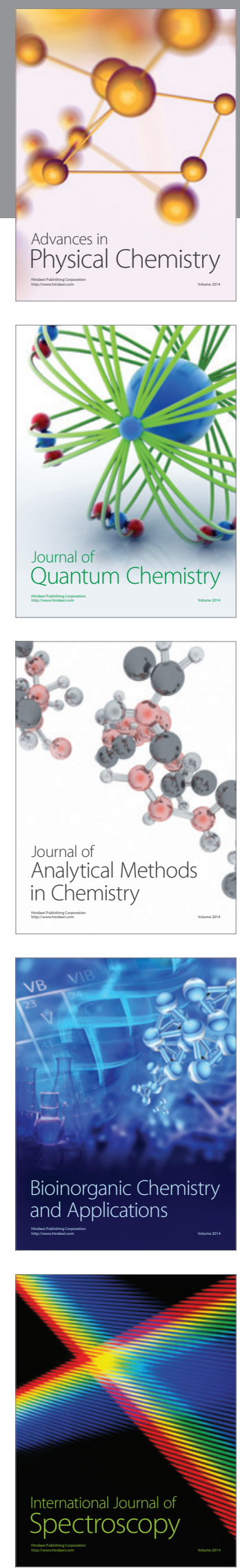